ROY, Reginald H., Débarquement et offensive des Canadiens en

Normandie. [Saint-Laurent], Éditions du Trécarré, en collaboration avec le Musée canadien des civilisations et les Musées nationaux du Canada, coll. « Publication d'histoire militaire ", no 19 du Musée canadien de la Guerre, 1986.471 p. Traduit par Roland Marquis. 29,95 \$

\title{
Jean-Pierre Gagnon
}

Volume 42, numéro 2, automne 1988

URI : https://id.erudit.org/iderudit/304699ar

DOI : https://doi.org/10.7202/304699ar

Aller au sommaire du numéro

\section{Éditeur(s)}

Institut d'histoire de l'Amérique française

ISSN

0035-2357 (imprimé)

1492-1383 (numérique)

Découvrir la revue

Citer ce compte rendu

Gagnon, J.-P. (1988). Compte rendu de [ROY, Reginald H., Débarquement et offensive des Canadiens en Normandie. [Saint-Laurent], Éditions du Trécarré, en collaboration avec le Musée canadien des civilisations et les Musées nationaux du Canada, coll. « Publication d'histoire militaire ", $\mathrm{n}^{0} 19$ du Musée canadien de la Guerre, 1986. 471 p. Traduit par Roland Marquis. 29,95 \$]. Revue d'histoire de l'Amérique française, 42(2), 302-303. https://doi.org/10.7202/304699ar 
ROY, Reginald H., Débarquement et offensive des Canadiens en Normandie. [Saint-Laurent], Éditions du Trécarré, en collaboration avec le Musée canadien des civilisations et les Musées nationaux du Canada, coll. «Publication d'histoire militaire», no 19 du Musée canadien de la Guerre, 1986. 471 p. Traduit par Roland Marquis. 29,95\$

Le 40e anniversaire de la bataille de Normandie a provoqué la parution, au Canada, de quelques livres, dont celui de Reginald $\mathrm{H}$. Roy, publié en anglais en 1984 sous le titre 1944: The Canadians in Normandy. Dans le passé, les Canadiens désireux de se renseigner sur le sujet n'avaient à leur disposition que la savante analyse de C. P. Stacey, La campagne de la victoire. Tel n'est plus le cas aujourd'hui. En plus de l'ouvrage de Roy, ils peuvent recourir au livre de J. L. Granatstein et D. Morton, Bloody Victory, et à ceux de Terry Copp et Robert Vogel, Maple Leaf Route: Caen et Maple Leaf Route: Falaise.

Ces historiens ont donné à leur ouvrage un caractère propre. Pour sa part, Roy a voulu faire le récit des combats auxquels les Canadiens ont participé pendant la bataille de Normandie. Il a tenté, écrit-il, «de décrire, à l'intention d'une nouvelle génération, la contribution des officiers, sous-officiers et simples soldats canadiens à la campagne de Normandie, de même que d'éveiller des souvenirs chez les vétérans de cette campagne (p. 13)». Il s'agit donc essentiellement d'un ouvrage d'histoire-batailles qui aura le don de charmer les amateurs du genre.

Quant au lecteur non initié à l'histoire militaire, il trouvera dans ce livre une brève description de plusieurs éléments de l'arrière-plan humain et organisationnel dans lequel fantassins et blindés se portèrent au combat. Ainsi, l'auteur dit quelques mots des préoccupations du soldat au front (p. 59); des préparatifs à l'attaque (p. 80,219,326); de la part prise à la bataille par l'aviation et l'artillerie (p. 21, 60-61, 344); de la vie à l'arrière (p. 97); du repos au quartier général du corps d'armée (p. 365-366); du rôle des unités de soutien: génie (p. 63-64, 357), transmissions (p. 64, 220), intendance (p. 220-221); 
de l'influence d'incidents impondérables sur le cours des opérations (p. 327); sur les difficultés de la marche en avant (p. 345), sur celles de nettoyer villes et villages de la présence ennemie (p. 410), etc. On se demande bien toutefois pourquoi l'auteur a attendu à la page 260 , pour expliquer la composition d'une division d'infanterie et d'une division blindée. Le lecteur trouvera dans les appendices d'autres renseignements sur l'organisation militaire. L'auteur a aussi relevé (p. 222, 322, 344) certains principes de guerre dont le commandant du 2e corps d'armée canadien, le lieutenant-général G. G. Simonds, s'est inspiré dans l'organisation des attaques lancées par ses troupes. Enfin, Roy n'a pas manqué de relever les bourdes commises par les bombardiers anglais et américains (p. 269, 328-329, 361-364) quand ils lâchèrent leurs bombes sur les soldats canadiens. À juste titre, d'ailleurs, il a même qualifié de «tout à fait stupide» la procédure que la Royal Air Force imposait à l'armée dans des cas semblables. En conséquence, «il n'existait aucun moyen rapide et efficace pour interrompre un bombardement erroné lorsque celui-ci avait commencé» (p. 364).

Les observations de l'auteur sur les à-côtés des actions des fantassins et des blindés informent les lecteurs non familiers avec l'histoire militaire. Elles permettent aux autres de prendre un moment de répit, avant de replonger dans le récit des opérations. Commencée le 6 juin 1944 par le débarquement des troupes alliées sur les plages normandes, la bataille de Normandie prit fin le 21 août suivant, après que les alliés fussent parvenus à prendre les Allemands dans un étau à Falaise. L'auteur décrit tour à tour le débarquement lui-même (6 juin), la bataille de la tête de pont (7-30 juin), l'attaque de Carpiquet (4 juillet), la prise de Caen (8-9 juillet), la bataille de la crête de Bourguébus (18-21 juillet), la bataille de la crête de Verrières et de Tilly-la-Campagne (25 juillet), l'opération «Totalize» (7-10 août), lancée de part et d'autre de la Nationale Caen-Falaise, l'opération «Tractable» (14-16 août), menée pour ouvrir une trouée en direction de Falaise, et la fermeture de la brèche de Falaise (17-21 août).

Dans son avant-propos, l'auteur dit avoir écrit son livre «pour les anciens combattants et pour les autres, pour les officiers autant que pour les simples soldats, pour les spécialistes de l'art militaire aussi bien que pour les profanes». Il s'agit là d'un but louable, mais il n'est pas facile de rejoindre ainsi des publics aussi différents, surtout quand il faut rendre compte d'opérations militaires complexes. Roy a fait des efforts méritoires pour rendre son livre accessible au plus grand nombre. Mais nous ne croyons pourtant pas que le profane pourra suivre facilement le déroulement des combats nombreux de la bataille de Normandie. Les cartes, d'ailleurs, reprises de l'ouvrage de Stacey, s'adressent plus au spécialiste qu'au non-initié et leur reproduction laisse à désirer. Ajoutons que Roy a parsemé son récit de témoignages qu'il a recueillis d'officiers supérieurs qui ont participé à cette bataille cruciale. Trois régiments canadiens-français y ont pris part: le Régiment de Maisonneuve, les Fusiliers Mont-Royal et le Régiment de la Chaudière. 